\title{
Glycine transporters GlyT1 and GlyT2 are differentially modulated by glycogen synthase kinase $3 \beta$
}

\author{
Esperanza Jiménez ${ }^{\text {a, b, c }}$, Enrique Núñez ${ }^{\text {a, b, c }}$, Ignacio Ibáñez ${ }^{\text {a, b, c }}$, Francisco Zafra ${ }^{\text {a, b, c }}$, \\ Carmen Aragón a, b, c, 1 , Cecilio Giménez ${ }^{\text {a, b, c, *, } 1}$ \\ ${ }^{a}$ Centro de Biología Molecular Severo Ochoa, Universidad Autónoma de Madrid, Consejo Superior de Investigaciones Científicas, 28049 Madrid, Spain \\ b Centro de Investigación Biomédica en Red de Enfermedades Raras, ISCIII, Madrid, Spain

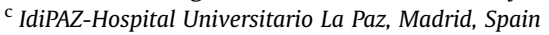

\section{A R T I C L E I N F O}

\section{Article history:}

Received 25 March 2014

Received in revised form

8 September 2014

Accepted 16 September 2014

Available online 6 October 2014

\section{Keywords:}

Glycinergic neurotransmission

GSK3 $\beta$

GlyT1

GlyT2

Pharmacological inhibitors

Hereditary hyperekplexia

\begin{abstract}
A B S T R A C T
Inhibitory glycinergic neurotransmission is terminated by the specific glycine transporters GlyT1 and GlyT2 which actively reuptake glycine from the synaptic cleft. GlyT1 is associated with both glycinergic and glutamatergic pathways, and is the main regulator of the glycine levels in the synapses. GlyT2 is the main supplier of glycine for vesicle refilling, a process that is vital to preserve the quantal glycine content in synaptic vesicles. Therefore, to control glycinergic neurotransmission efficiently, GlyT1 and GlyT2 activity must be regulated by diverse neuronal and glial signaling pathways. In this work, we have investigated the possible functional modulation of GlyT1 and GlyT2 by glycogen synthase kinase 3 (GSK3 $\beta$ ). This kinase is involved in mood stabilization, neurodegeneration and plasticity at excitatory and inhibitory synapses. The co-expression of GSK3 $\beta$ with GlyT1 or GlyT2 in COS-7 cells and Xenopus laevis oocytes, leads to inhibition and stimulation of GlyT1 and GlyT2 activities, respectively, with a decrease of GlyT1, and an increase in GlyT2 levels at the plasma membrane. The specificity of these changes is supported by the antagonism exerted by a catalytically inactive form of the kinase and through inhibitors of GSK3 $\beta$ such as lithium chloride and TDZD-8. GSK3 $\beta$ also increases the incorporation of 32Pi into GlyT1 and decreases that of GlyT2. The pharmacological inhibition of the endogenous GSK3 $\beta$ in neuron cultures of brainstem and spinal cord leads to an opposite modulation of GlyT1 and GlyT2.Our results suggest that GSK3 $\beta$ is important for stabilizing and/or controlling the expression of functional GlyTs on the neural cell surface.
\end{abstract}

(c) 2014 Elsevier Ltd. All rights reserved.

\section{Introduction}

Inhibitory glycinergic neurotransmission is terminated by the specific glycine transporters GlyTs (GlyT1 and GlyT2) which

\footnotetext{
Abbreviations: AMPA, $\alpha$-amino-3-hydroxy-5-methyl-4-isoxazolepropionic acid; CNS, central nervous system; COS-7, CV-1 (simian) in origin and carrying the SV40 genetic material cells; DTT, dithiothreitol; EGTA, ethyleneglycoltetraacetic acid; EDTA, ethylenediaminetetraacetic acid; GABA, $\gamma$-aminobutyric acid; GlyT1, glycine transporter 1; GlyT2, glycine transporter 2; HEPES, 4-(2-hydroxyethyl)-1piperazineethanesulfonic acid; NMDA, N-methyl-D-aspartic acid; PBS, phosphate buffer saline; SDS-PAGE, sodium dodecyl sulfate-polyacrylamide gel electrophoresis; SLC6, solute carrier 6: TDZD-8, 4-benzyl-2-methyl-1, 2, 4-thiadiazolidine-3,5dione.

* Corresponding author. Centro de Biología Molecular Severo Ochoa, Universidad Autónoma de Madrid, C / Nicolás Cabrera, 1, 28049 Madrid, Spain. Tel.: +34 91196 4629.

E-mail address: cgimenez@cbm.csic.es (C. Giménez).

1 These authors share last authorship.
}

actively reuptake glycine from the synaptic cleft. GlyTs belong to the neurotransmitter: sodium symporter family (SLC6 gene family), which includes transporters for most of the neurotransmitters, serotonin, dopamine, norepinephrine and GABA, in the central nervous system (CNS) (Aragón and López-Corcuera, 2003). GlyT1 is associated with both glycinergic and glutamatergic pathways and is the main regulator of glycine levels in the synapses. The neuronal transporter GlyT2 recycles the neurotransmitter to the presynaptic terminal, a process that is absolutely necessary to preserve the quantal glycine content inside the synaptic vesicles (Apostolides and Trussell, 2013; Gomeza et al. 2003b; Harvey and Yee, 2013; Rousseau et al., 2008). Mouse gene disruption studies have revealed that constitutive deletion of either GlyT1 or GlyT2 is lethal (primarily as a result of excessive or deficient glycinergic inhibition, respectively), and suggest that alterations in GlyTs may underlie several human disorders (Aragón and López-Corcuera, 2005; Gomeza et al., 2003a, 2003b). These studies revealed the 
role of GlyTs as homeostatic regulators of glycine levels in glycinergic and glutamatergic pathways that controls the balance of neuronal excitation and inhibition within several neural circuits. GlyT1 and GlyT2 have been related to disorders of central and peripheral nervous system, such as schizophrenia, depression, epilepsy, obsessive-compulsive disorders, anxiety disorders, pain, alcohol dependence, breathing disorders and hereditary hyperekplexia (Harvey and Yee, 2013). Indeed, mutations in the gene encoding GlyT2 are the second main cause of hyperekplexia in humans (Carta et al., 2012; Eulenburg et al., 2006; Gimenez et al., 2012; Rees et al., 2006) and produce congenital muscular dystonia type 2 (CMD2) in Belgian Blue cattle (Gill et al., 2012). Moreover GlyT1 inhibitors may improve cognitive deficits of schizophrenia by increasing glycine levels around the NMDA receptors. GlyT1 inhibitors are being developed by the pharmaceutical industry, mostly intended for treatment of cortical NMDA receptor hypofunction in schizophrenia (Javitt, 2008; Pinard et al., 2010).

An analysis of knock-out animals proved that the modulation of glycine transporter expression and/or transport activity influenced glycine-mediated neurotransmission and opened a way to find therapeutic applications (Gomeza et al., 2003a, 2003b). The levels of active glycine transporters in the plasma membrane are controlled by several factors in a regulated manner (de Juan-Sanz et al., 2011; de Juan-Sanz et al., 2013a; de Juan-Sanz et al., 2013b; Fornes et al., 2008; Geerlings et al., 2001; Nuñez et al., 2008). In the CNS these regulatory pathways must be triggered by physiological stimuli or the activity of appropriate receptors (Jiménez et al., 2011).

Glycogen synthase kinase 3 (GSK3) is currently considered to be a multifunctional serine/threonine kinase involved in a wide spectrum of cellular processes such as glycogen metabolism, cell proliferation, neuronal function, oncogenesis or embryonic development (for recent reviews see: Rayasam et al., 2009; Wildburger and Laezza, 2012). Although the protein is expressed in nearly all tissues, its highest levels and activity are found in the CNS (Leroy and Brion, 1999; Woodgett, 1990). Two distinct, but closely related forms of GSK3, GSK3 $\alpha$ and GSK3 $\beta$, have been identified. GSK3 is constitutively active in resting cells and its activity can be inhibited by phosphorylation at serine residues (Ser21 for GSK3 $\alpha$ and Ser9 for GSK3 $\beta$ ) on their $\mathrm{N}$-terminal domain. By controlling the phosphorylation of these residues, neurons regulate GSK3 activity (for review see Doble and Woodgett, 2003). In animal models, the overexpression of GSK-3 induces increased vulnerability to mood-related behavioral disturbances and impaired socialization behavior (Mines et al., 2010; Polter et al., 2010). Furthermore, in clinical studies changes in the expression and activity of GSK-3 are found in schizophrenia (Emamian, 2012; Jope, 2003; Kozlovsky et al., 2001, 2002; Lovestone et al., 2007), mood disorders (Eldar-Finkelman, 2002; Jope, 2011), addictive behaviors (Miller et al., 2009, 2010) and Alzheimer's disease (Balaramanetal., 2006; Hooper et al., 2008; Kremer et al., 2011). Recently, the role of GSK3 $\beta$ has emerged in the pathogenesis of pain (Maixner et al., 2014).

Despite the pleiotropic effects of GSK3, or probably because of them, many of their molecular targets in the CNS have not yet been identified. Lately, GSK-3 has been proposed as a key element in plasticity at excitatory and inhibitory synapses in the CNS (Bradley et al., 2012). The molecular mechanisms underlying, at least partially, the role of GSK-3 in synaptic plasticity is through the regulation of NMDA and AMPA receptors endocytosis (Bradley et al., 2012; Chen et al., 2007; Wei et al., 2010).

Given the essential role of plasma membrane trafficking to control GlyTs activity in excitatory and inhibitory synapsis and the fact that GSK3 and glycine transporters share implication in some CNS disorders such as, neuropathic pain, schizophrenia and alcohol dependence, in this work we have investigated whether GSK3 is involved in the modulation of these transporters. Our results provide evidence of a differential regulation of GlyT1 and GlyT2 by GSK3 $\beta$ in heterologous and neuronal cells.

\section{Materials and methods}

2.1. Materials

Wistar rats were bred at the Centro de Biología Molecular Severo Ochoa (Madrid, Spain). The experiments were performed in accordance with the Royal Decree 1201/2005 of the Spanish Ministry of Presidency for the protection of animals used in scientific research.

$\left[{ }^{3} \mathrm{H}\right]$ Glycine (PERKIN ELMER) protein standards for sodium dodecyl sulfatepolyacrylamide gel electrophoresis (Precision Plus Standards) (Bio-Rad), and the Enhanced Chemiluminescence (ECL) Western blotting detection reagents were obtained from Amersham. GlyT2 inhibitor ALX-1393 O-[(2-Benzyloxyphenyl-3flurophenyl) methyl]-L-serine was purchased from Sigma. NFPS (ALX-5407) hydrochloride, $\mathrm{N}$-[3-(4'-Fluorophenyl)-3-(4'-phenylphenoxy) propyl]sarcosine hydrochloride was obtained from Axon Medchem. True-Fect-LipoTM was from United Biosystems (Rockville, MD), EZ-Link Sulfo-NHS-SSBiotin was from Pierce. pcDNA3 plasmid was purchased from Invitrogen, the Expand High Fidelity PCR system (Taq polymerase) and all restriction enzymes were obtained from Roche Applied Science. The pGEM-T easy cloning vector was purchased from Promega (Madison, WI) and the oligonucleotides used were synthesized by Sigma. The QuikChange Site-Directed Mutagenesis kit was from Stratagene (La Jolla, CA), nitrocellulose sheets were from Bio-Rad and fetal calf serum was supplied by Invitrogen.

Rat antibody against GlyT2 and rabbit antibody against GlyT1 have been previously characterized (Zafra et al., 1995). Antibody against GSK3 $\beta$ were from BD Transduction Laboratories. Anti-rabbit and anti-rat coupled to AlexaFluor ${ }^{\mathbb{B}} 555$ fluorophore for GlyT1 and GlyT2 and anti-mouse antibody coupled to AlexaFluor ${ }^{\mathbb{B}}$ 488 for GSK3 $\beta$ secondary antibodies were used.

All other chemicals were obtained from Sigma.

\subsection{Cell growth and transfection}

COS-7 cells (American Type Culture Collection) were grown in high glucose Dulbecco's modified Eagle's medium (DMEM) supplemented with $10 \%$ fetal bovine serum at $37{ }^{\circ} \mathrm{C}$ in an atmosphere of $5 \% \mathrm{CO}_{2}$. Transient expression in COS-7 cells was achieved using TrueFect-Lipo, according to the manufacturers' instructions. The cells were incubated for $48 \mathrm{~h}$ at $37^{\circ} \mathrm{C}$ and then analyzed biochemically or by immunofluorescence and/or in transport assays.

\subsection{Plasmid constructs}

GSK3 plasmids: prCMVGSK3 $\beta$ and prCMV K85R GSK3 $\beta$ (DN GSK3 $\beta$ ) were kindly provided by Dr Felix Hernandez (Centro de Biología Molecular Severo Ochoa, Universidad Autónoma de Madrid, Spain). GlyT1 and GlyT2 cDNAs were subcloned into pcDNA3, as described (Smith et al., 1992; Liu et al., 1993).

For electrophysiological recordings, the cDNAs for GlyT1, GlyT2, wt GSK3 $\beta$, and DN GSK3 $\beta$ were subcloned into the vector pSP64T, which contains the 5-and 3-UTRs of the Xenopus laevis globin gene (provided by Dr Carmen Montiel, Universidad Autónoma de Madrid). All constructs and mutants were confirmed by sequencing.

\subsection{Expression in Xenopus oocytes}

The cDNAs cloned into pSP64T were linearized with Xbal (GSK3) or SalI (GlyT2 and GlyT1) and the cRNAs were transcribed with SP6 polymerase and capped with 5,7-methylguanosine using the mMESSAGE mMACHINE SP6 RNA kit (Ambion Inc.). $X$. laevis frogs were obtained from Xenopus Express (France) and oocytes were harvested from $X$. laevis anesthetized in $0.1 \%(\mathrm{w} / \mathrm{v})$ Tricaine methanesulfonate solution in tap water. All these procedures were performed in accordance with the Spanish and European guidelines for the prevention of cruelty to animals. The follicular membrane was removed by incubation in a medium $(90 \mathrm{mM} \mathrm{NaCl}, 1 \mathrm{mM}$ $\mathrm{KCl}, 1 \mathrm{mM} \mathrm{MgCl}$, $5 \mathrm{mM}$ HEPES ( $\mathrm{pH}$ 7.4) containing 300 units/ml collagenase (Type 1; Sigma) for $1 \mathrm{~h}$. cRNAs encoding either GlyT1 or GlyT1:GSK3 $\beta$, GlyT1:GSK3 $\beta$ DN or GlyT2 or GlyT2:GSK3 $\beta$, GlyT2:GSK3 $\beta$ DN (50 ng) were injected into defolliculated stage $\mathrm{V}$ and VI $X$. laevis oocytes. The oocytes were maintained in Barth's medium $\left(88 \mathrm{mM} \mathrm{NaCl}, 1 \mathrm{mM} \mathrm{KCl}, 0.33 \mathrm{mM} \mathrm{Ca}\left(\mathrm{NO}_{3}\right)_{2}, 0.41 \mathrm{mM} \mathrm{CaCl}_{2}, 0.82 \mathrm{mM} \mathrm{MgSO}_{4}, 2.4 \mathrm{mM}\right.$ $\mathrm{NaHCO}_{3}, 10 \mathrm{mM}$ HEPES (pH7.4) and transport or electrophysiological experiments were carried out 5 days later.

\subsection{Two-microelectrode voltage clamp recordings of Xenopus oocytes}

Electrophysiological recordings were obtained after incubating the injected oocytes at $18{ }^{\circ} \mathrm{C}$ in standard oocyte solution $(100 \mathrm{mM} \mathrm{NaCl}, 2 \mathrm{mM} \mathrm{KCl}, 1 \mathrm{mM}$ $\mathrm{CaCl}_{2}, 1 \mathrm{mM} \mathrm{MgCl}, 10 \mathrm{mM}$ HEPES, $\mathrm{pH}$ adjusted to 7.5 with $\mathrm{HCl}$ ). A two-electrode voltage clamp was used to measure and control the membrane potential and to monitor the capacitative currents using Axoclamp 900A (Axon Instruments). The two electrode signals were digitized by a Digidata 1440A (Axon Instruments) and both instruments were controlled by the pCLAMP software (Axon Instruments). The results were analyzed by Clampfit 10.2 software (Axon Instruments). The 
recordings were performed at room temperature (RT) using standard micropipettes filled with $3 \mathrm{M} \mathrm{KCl}$ (resistance varied between 0.5 and $2 \mathrm{M} \Omega$ ). Oocytes were held at $-40 \mathrm{mV}$ and currents were subjected to low pass filtering at $100 \mathrm{~Hz}$.

\subsection{Neuron-enriched brainstem primary cultures}

Brainstem primary cultures were performed as described (Kaech and Banker, 2006) with modifications. Brainstems and spinal cords from fetuses from animals 16 days post-conception were isolated in Hanks balanced salt solution (Invitrogen) and dissociated with $0.25 \%$ Tripsin (Invitrogen) and $4 \mathrm{mg} / \mathrm{ml}$ DNAase (Sigma). Cells were incubated for $4 \mathrm{~h}$ in plating buffer (Dulbecco's Modified Eagle Medium, Invitrogen, containing $10 \%$ fetal calf serum and supplemented with $10 \mathrm{mM}$ glucose, $10 \mathrm{mM}$ sodium pyruvate, $0.5 \mathrm{mM}$ glutamine, $0.05 \mathrm{mg} / \mathrm{ml}$ gentamicin, $0.01 \%$ streptomycin, $100 \mathrm{~m}$-units $/ \mathrm{ml}$ penicillin $\mathrm{G}$ ) and buffer was then replaced by culture medium (Neurobasal/B27 50:1 by vol, Invitrogen, containing $0.5 \mathrm{mM}$ glutamine). At 2 days in vitro (DIV) cytosine arabinoside (AraC) was added to a $10 \mu \mathrm{M}$ final concentration and was progressively diluted with fresh medium added every 5 days until cultures were used (12-15 DIV). Cells were plated on poly-lysine $(13 \mu \mathrm{g} / \mathrm{ml})$-coated 24 -well-plates at density of 200,000 cells/well for transport assays.

\subsection{Immunofluorescence of primary neurons from rat brainstem and spinal cord}

Primary neurons were analyzed by immunofluorescence as reported previously (de Juan-Sanz et al., 2013b). The primary antibodies used in this work were incubated overnight at $4{ }^{\circ} \mathrm{C}$ using the following dilutions: GlyT2 (1:500), GlyT1 (1:2000), GSK3 $\beta$ (1:1000). The cells were visualized by confocal microscopy on an inverted microscope AXIOVERT200 (Zeiss).

\subsection{Electrophoresis and immunoblotting}

SDS-PAGE was performed on $10 \%$ polyacrylamide gels in the presence of 2 mercaptoethanol. After electrophoresis, the protein samples were transferred to nitrocellulose membranes in a semidry electroblotting system at $1.2 \mathrm{~mA} / \mathrm{cm}^{2}$ for $2 \mathrm{~h}$ (LKB) using a transfer buffer containing $192 \mathrm{mM}$ glycine and $25 \mathrm{mM}$ Tris $-\mathrm{HCl}(\mathrm{pH}$
8.3). Nonspecific binding to the membrane was blocked by incubating the filter with $5 \%$ non-fat milk protein in $10 \mathrm{mM}$ Tris- $\mathrm{HCl}\left(\mathrm{pH} \mathrm{7.5),} 150 \mathrm{mM} \mathrm{NaCl}\right.$ for $4 \mathrm{~h}$ at $25^{\circ} \mathrm{C}$. The membrane was then probed overnight at $4{ }^{\circ} \mathrm{C}$ with the diluted primary antibody which was detected after washing with an IgG peroxidase-linked secondary antibody. The labeled bands were visualized by ECL and quantified by densitometry on a GS-710 calibrated imaging densitometer from Bio-Rad with Quantity One software by using film exposures in the linear range.

\subsection{Transport assays}

Glycine transport assays-uptake assays in COS-7 cells and brainstem primary neuronal cultures were performed at $37^{\circ} \mathrm{C}$ in PBS as previously described (Fornes et al., 2008) with modifications. For GlyT1 activity determination, uptake solution contained $2 \mu \mathrm{Ci} / \mathrm{ml}\left[{ }^{3} \mathrm{H}\right]$ glycine (1.6 TBq/mmol; NEN Life Science Products), cold glycine $(10 \mu \mathrm{M}$ final concentration) plus $200 \mathrm{nM}$ ALX-1393 to inhibit glycine transport by GlyT2 with or without the specific GlyT1 inhibitor NFPS ( $5 \mu \mathrm{M})$ to measure background glycine accumulation. For GlyT2 activity determination, uptake solution contained the radioactive substrate plus $5 \mu \mathrm{M}$ NFPS to inhibit glycine transport by GlyT1 with or without the specific GlyT2 inhibitor ALX-1393 (200 nM). After 10 min incubation, aliquots were obtained for scintillation counting and protein quantification (Bradford method).

\subsection{Protein determination}

Protein concentrations were determined with the Bio-Rad Protein Determination kit using bovine serum albumin (BSA) as the standard.

\subsection{Cell surface biotinylation}

COS-7 cells were plated at $70 \%$ confluence in $60 \mathrm{~mm}$ cell culture plates and transfected as indicated above. After 2 days, the cells were washed with ice-cold PBS ( $137 \mathrm{mM} \mathrm{NaCl}, 2.7 \mathrm{mM} \mathrm{KCl}, 4.3 \mathrm{mM} \mathrm{Na}_{2} \mathrm{HPO}_{4} 7 \mathrm{H}_{2} \mathrm{O}, 1.4 \mathrm{mM} \mathrm{KH}_{2} \mathrm{PO}_{4}, \mathrm{pH} 7.3$ ) and the cell surface proteins were labeled for $20 \mathrm{~min}$ at $4{ }^{\circ} \mathrm{C}$ by incubating them in a $1 \mathrm{ml}$ solution containing the non-permeable Sulfo-NHS-SS-Biotin reagent $(1 \mathrm{mg} / \mathrm{ml}$ in PBS). The cells were then washed with $2 \mathrm{ml}$ of PBS plus $100 \mathrm{mM}$ lysine for $20 \mathrm{~min}$ to quench the reagent. After three additional washes with PBS, the cells were lysed for
A

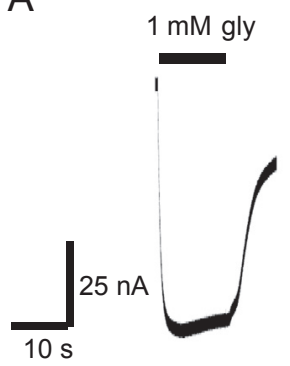

GlyT1

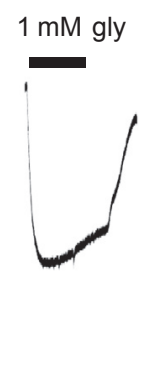

GlyT1:GSK3 $\beta$

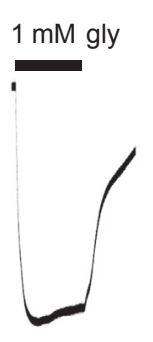

GlyT1:DN GSK3 $\beta$

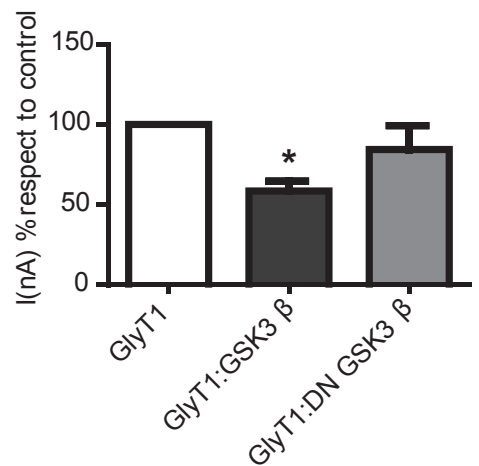

B
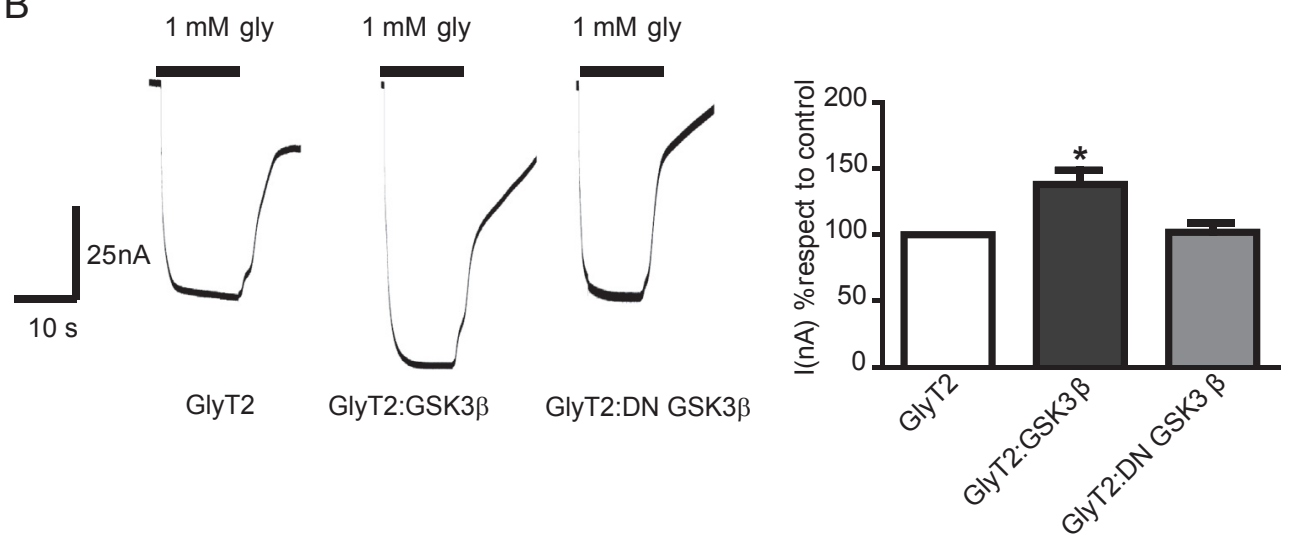

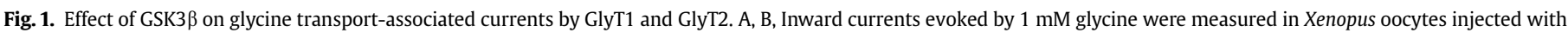

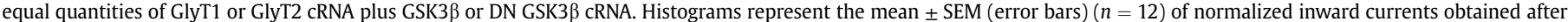

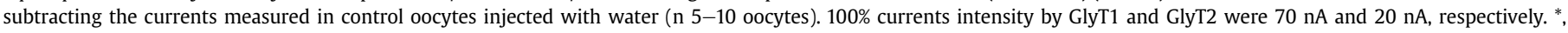
statistically significantly different ( $p<0.05$; ANOVA with Tukey's post-hoc test) from the current in Xenopus oocytes expressing GlyT1/GlyT2 alone. 
$30 \mathrm{~min}$ in $1 \mathrm{ml}$ of lysis buffer ( $150 \mathrm{mM} \mathrm{NaCl}, 5 \mathrm{mM}$ EDTA, $50 \mathrm{mM}$ HEPES-Tris, $0.25 \%$ sodium deoxycholate, $1 \%$ Triton X-100, $0.1 \%$ SDS, pH 7.4), and the lysate was cleared by centrifugation at $14,000 \mathrm{~g}$ for $10 \mathrm{~min}$. The biotinylated proteins were finally recovered by incubating the cleared lysate for $2 \mathrm{~h}$ at RT with streptavidin-agarose beads. After washing the beads three times with $1 \mathrm{ml}$ of the lysis buffer, the protein bound to the beads was eluted in $2 \times$ Laemmli sample buffer, separated by SDSPAGE, and analyzed in Western blots. Biotinylated GlyT1 and GlyT2 were revealed with its correspondent primary antibodies.

For primary neuron cultures, biotinylation was performed as described previously (Jiménez et al., 2011).

\subsection{Metabolic labeling and immunoprecipitation}

COS-7 cells were plated on p35 dishes and transfected with True-Fect-LipoTM according to the manufacturer's instructions. Two days later, the cells were incubated in phosphate-free DMEM for 2 h with TDZD-8 $(10 \mu \mathrm{M})$ or vehicle and then metabolically labeled with $0.03 \mathrm{mCi} / \mathrm{ml}^{32} \mathrm{P}$-labeled inorganic phosphate $\left(\mathrm{H}_{3} \mathrm{PO}_{4}\right)$ with TDZD-8 $(10 \mu \mathrm{M})$ or vehicle. After labeling for $3.5 \mathrm{~h}$, the cells were rinsed with Tris-buffered saline solution, and harvested in immunoprecipitation lysis buffer (50 mM Tris- $\mathrm{HCl}$, (pH 8.0), $150 \mathrm{mM} \mathrm{NaCl}, 1 \%$ Nonidet-P40, 0.1\% SDS, 0.5\% sodium deoxycholate, $2 \mathrm{mM}$ EDTA, $50 \mathrm{mM} \mathrm{NaF}, 0.2 \mathrm{mM} \mathrm{NaVO}_{3}$ ). After incubation for $30 \mathrm{~min}$ at $4{ }^{\circ} \mathrm{C}$, cell debris was removed by centrifugation at $12,000 \mathrm{~g}$ for $10 \mathrm{~min}$, and the supernatant was used for immunoprecipitation. The immunoprecipitated material was resolved by electrophoresis as described below and, after drying, the gels were submitted to autoradiography.

\subsection{Immunoprecipitation}

Transiently transfected cells were solubilized in radioimmune precipitation assay buffer ( $50 \mathrm{mM}$ Tris- $\mathrm{HCl}, \mathrm{pH} 7.5$ ), $1 \%$ Nonidet $\mathrm{P}-40,0.5 \%$ sodium deoxycholate, $150 \mathrm{mM} \mathrm{NaCl}, 1 \mathrm{mM}$ EGTA, $2 \mathrm{mM}$ EDTA, $0.1 \mathrm{mM}$ DTT. The solubilized material was centrifuged at $12,000 \mathrm{~g}$ for $20 \mathrm{~min}$, and the supernatant was incubated overnight at $4{ }^{\circ} \mathrm{C}$ with the desired antibodies $(2 \mu \mathrm{g} / \mathrm{ml})$. Subsequently, $40 \mu \mathrm{l}$ of protein A crosslinked or protein $G$ cross-linked to agarose beads (Sigma) was added, and the mixture was incubated for $1 \mathrm{~h}$ at $4{ }^{\circ} \mathrm{C}$ with constant rotation. The beads were washed five times with ice-cold lysis buffer before adding SDS-PAGE sample buffer to each sample. The bound proteins were dissociated from the beads by heating at $92^{\circ} \mathrm{C}$ for 3 min before they were resolved on 10\% gels by SDS-PAGE as described below.

\subsection{Statistics}

Data are provided as means \pm SEM, $n$ represents the number of independent experiments. In order to test the normality of data distribution we used the Kolmogorov-Smirnov test obtaining a $p$ value $>0.05$. All data were tested for significance using ANOVA, as applicable and only results with $p<0.05$ were considered statistically significant.

\section{Results}

\subsection{GSK3 $\beta$ differentially modulates GlyT1 and GlyT2 activity in Xenopus oocytes and COS-7 cells}

Glycinergic neurotransmission is controlled efficiently by the coordinated operation of glycine transporters (GlyTs) that are presumably regulated by diverse neuronal and glial signaling pathways. As GSK3 $\beta$ is a central kinase regulating many aspects of brain physiology, from cell metabolism to cell differentiation, we decided to investigate the possible functional modulation between the GSK3 $\beta$ signaling pathway and the glycine transporters GlyT1 and GlyT2.

In order to elucidate the effect of GSK3 $\beta$ on the transport activity of GlyTs we used X. laevis oocytes and COS-7 cells as heterologous expression systems. Firstly, we co-expressed either GlyT1 or GlyT2
A
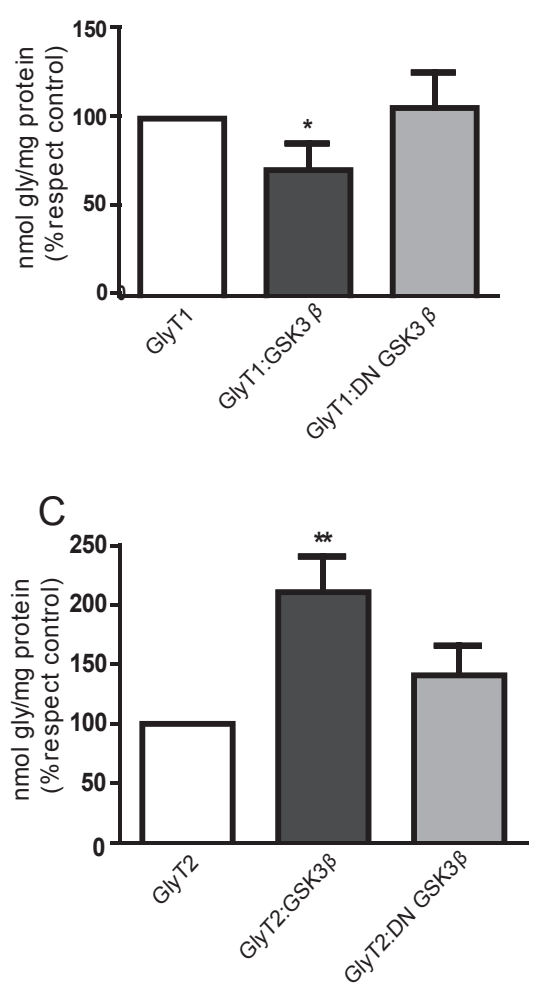

$\mathrm{B}$
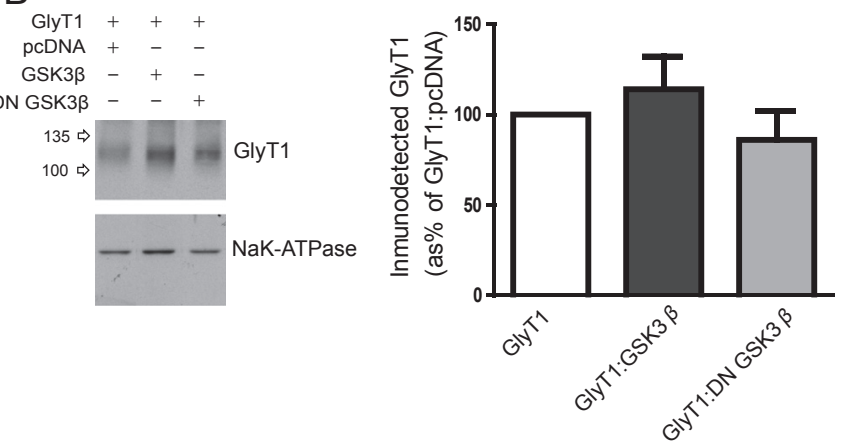

D
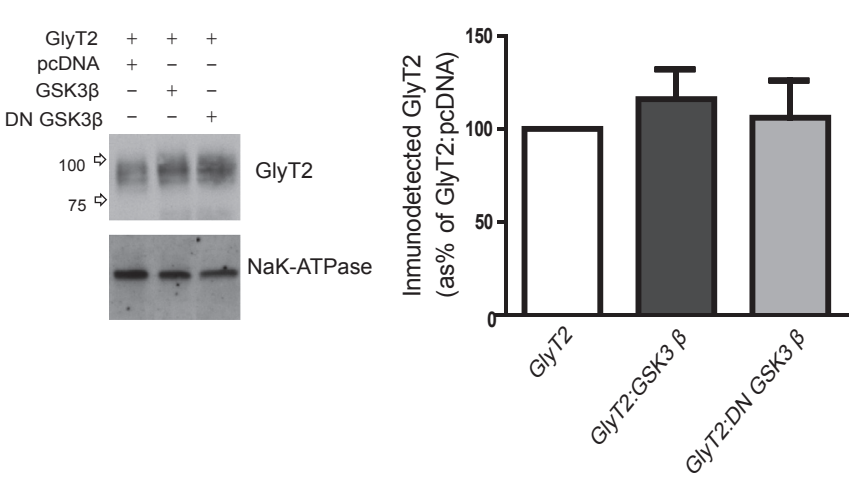

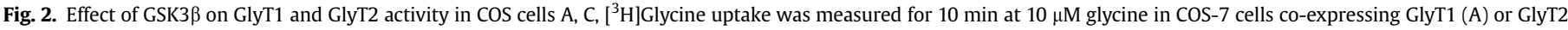

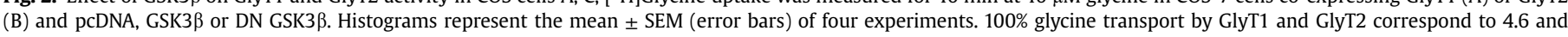

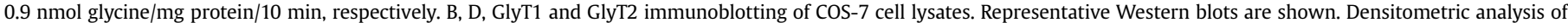

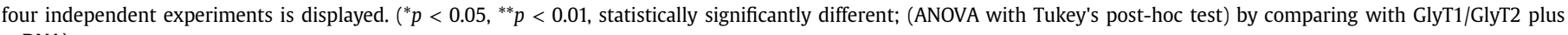
pcDNA). 
with GSK3 $\beta$, or a dominant negative form of the kinase (DN GSK3 $\beta$ ) in Xenopus oocytes by injecting the respective encoding cRNAs. The ionic currents associated with the glycine transport were measured four days after injection.

Electrogenic glycine transport was minimal in non-injected or water-injected oocytes (not shown) indicating the absence of basal glycine-induced currents in the control oocytes. In voltage-clamped oocytes expressing GlyT1 or GlyT2, glycine $(1 \mathrm{mM})$ induced an inward current (Ig) reflecting electrogenic entry of $\mathrm{Na}^{+}$associated to the glycine transport (Fig 1A, B). The co-expression of GSK3 $\beta$ caused a $42 \pm 13 \%$ reduction in the transport current mediated by GlyT1 and by contrast, a $46 \pm 24 \%$ increase in the transport currents by GlyT2. Consistently, these changes were not seen when the transporters were co-expressed with a catalytically inactive form (dominant negative) of GSK3 $\beta$, as the current intensity by GlyT1 was $84 \pm 33 \%$ and by GlyT2 was $102 \pm 14 \%$ by comparing with the control (Fig. 1A, B)

These results were further confirmed in the COS-7 mammalian cell expression system. In agreement with the voltage clamp measurements, co-expression of GSK3 $\beta$ with glycine transporters resulted in a stimulation or inhibition of glycine transport by GlyT2 $(211 \pm 30 \%)$ or by GlyT1 $(71 \pm 15 \%)$, respectively. This differential effect also disappeared when the dominant negative form of GSK3 $\beta$ was over-expressed (GlyT2 activity was $141 \pm 25 \%$ and GlyT1 activity was $106 \pm 20 \%$ respect to the control) (Fig. 2). To rule out unspecific effects due to different levels of expressed transporters, the total protein from different experiments was quantified by densitometry (representative western blots are shown in Fig. 2B, D). No significant variations in the expression levels of GlyT1 and GlyT2 (Fig 2B, D) confirm that observed functional changes (Fig. 2A and $C)$ are by GSK3 $\beta$ and DN GSK3 $\beta$.

\subsection{Kinetic parameters of GlyT1 and GlyT2 are modified by GSK3 $\beta$ overexpression}

Kinetic analysis of $\left[{ }^{3} \mathrm{H}\right.$ ]glycine transport by GlyT1 and GlyT2 in COS-7 cells showed that in each case, the maximum rate of transport ( $\left.V_{\max }\right)$ was mainly affected by GSK3 $\beta$ with mild changes in the $\mathrm{Km}$. A decrease in the GlyT1 $V_{\max }$ from $173.1 \pm 63.3 \mathrm{nmol}$ gly/ $\mathrm{mg}$ protein $/ 10 \mathrm{~min}$ to $31.7 \pm 2.1 \mathrm{nmol} \mathrm{gly} / \mathrm{mg}$ protein $/ 10 \mathrm{~min}$, and an increase in the GlyT2 $V_{\max }$ from $36.5 \pm 7.4 \mathrm{nmol}$ gly $/ \mathrm{mg}$ protein/ $10 \mathrm{~min}$ to $132.0 \pm 2.1 \mathrm{nmol} \mathrm{gly} / \mathrm{mg}$ protein $/ 10 \mathrm{~min}$ was observed. This modification was not produced when the negative dominant of GSK3 $\beta$ is co-expressed (Fig. 3).

\subsection{GSK3 $\beta$ alters GlyT1 and GlyT2 plasma membrane expression}

To test the possibility that the observed changes in $V_{\max }$ were due to variations in the plasma membrane expression of glycine transporters, cell surface proteins were labeled with the nonpermeant reagent sulfo-NHS-biotin, isolated with streptavidineagarose beads, and quantified by immunoblotting. Consistent with the functional results, Fig. 4 shows a decrease of $26 \pm 4 \%$ of GlyT1 plasma membrane level and an increase of $339 \pm 12 \%$ of GlyT2 surface amount, upon co-expression with GSK3 $\beta$. These changes were not observed in the presence of the dominant negative form of GSK3 $\beta$.

\subsection{GSK3 $\beta$ inhibitors abolish the kinase modulation of the glycine transporters}

As GSK3 $\beta$ presents a high activity in basal situation, and signaling pathways often operate through the inhibition of GSK3 $\beta$ activity (Doble and Woodgett, 2003), we used GSK3 $\beta$ inhibitors to verify the potential involvement of GSK3 $\beta$ in the GlyT1 and GlyT2 modulation. Despite its relative specificity, lithium is one of the best characterized inhibitors of GSK3 $\beta$ (Klein and Melton, 1996; Ryves and Harwood, 2001). Pretreatment of COS-7 cells co-expressing GSK3 $\beta$ and GlyT1, or GlyT2, with $5 \mathrm{mM}$ lithium chloride for $3 \mathrm{~h}$, prevented the high stimulation of GlyT2 (from $253 \pm 12 \%$ of control to $84 \pm 6 \%$ ) and the inhibition of GlyT1 (from $86 \pm 3,5 \%$ of control to $102 \pm 6 \%$ ) exerted by GSK3 $\beta$. Furthermore, similar results were obtained when cells were preincubated with $10 \mu \mathrm{M}$ TDZD-8, a highly specific non-ATP-competitive GSK3 inhibitor (GlyT2:GSK3 $\beta$ from $253 \pm 12 \%$ of control to $81 \pm 8 \%$ and GlyT1:GSK3 $\beta$ from $86 \pm 3.5 \%$ of control to $107 \pm 6 \%$ ) (Fig. $5 A, B$ ). The dramatic change in the GlyT2 activity in response to inhibitors and the marginal effect on GlyT1 activity are consistent with the larger effect of GSK3 $\beta$ on GlyT2 regarding GlyT1. Therefore, the reversal of inhibition is more evident in the case of GlyT2.

\subsection{Effect of GSK3 $\beta$ overexpression on GlyT1 and GlyT2 phosphorylation}

We studied the possible phosphorylation of these transporters by GSK3 $\beta$. COS-7 cells transfected with glycine transporters in the presence or absence of GSK3 $\beta$ or DN GSK3 $\beta$ were metabolically labeled with $\left[{ }^{32} \mathrm{P}\right] \mathrm{Pi}$ and immunoprecipitated with anti-GlyT1 and anti-GlyT2 antibodies. Finally, the immunoprecipitated material was analyzed by SDS-PAGE and autoradiography. The results showed that under basal conditions there was a weak incorporation of ${ }^{32} \mathrm{P}$ into lanes transfected either with GlyT1 (Fig. 6A) or

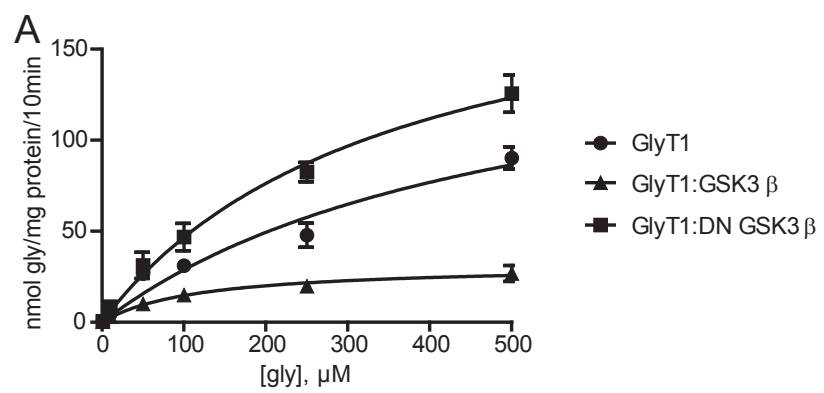

$$
\begin{array}{cccc} 
& \text { GlyT1:pcDNA } & \text { GlyT1:GSK3 } \beta & \text { GlyT1:DN GSK3 } \beta \\
\text { Vmax } & 173.1 \pm 63.3 & 31.7 \pm 2.1^{*} & 209.7 \pm 20.5 \\
\mathrm{Km} & 351.2 \pm 31.5 & 116.1 \pm 21.3 & 350.0 \pm 65.5
\end{array}
$$

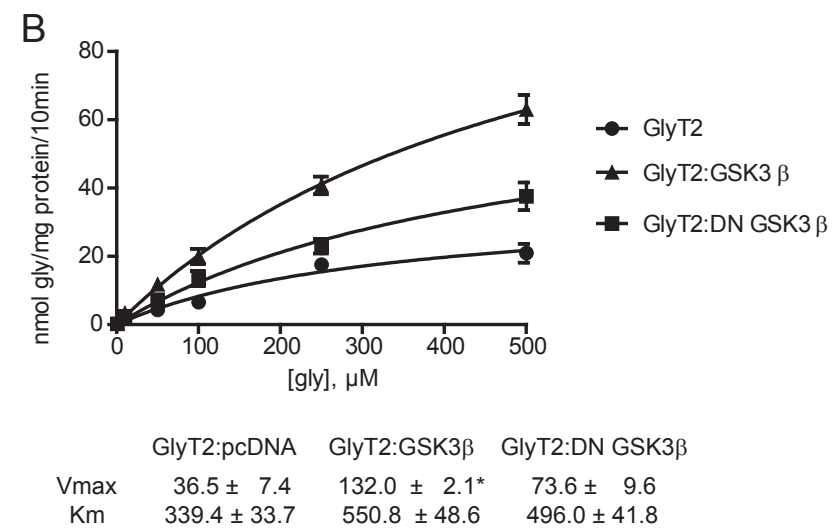

Fig. 3. GSK3 $\beta$ alters kinetic parameters of GlyT1 and GlyT2. A, B, $\left[{ }^{3} \mathrm{H}\right]$ Glycine uptake at the concentrations indicated was measured for $10 \mathrm{~min}$ in COS-7 cells transfected with GlyT1(A) or GlyT2(B) and pcDNA, GSK3 $\beta$ or DN GSK3 $\beta$. $V_{\max }$ is expressed as nmol glycine/mg prot/min and $\mathrm{Km}$ in $\mu \mathrm{M}$. The results represent the means $\pm \mathrm{SEM}$ of three triplicate determinations $\left({ }^{*}\right.$, statistically significantly different $(p<0.05$; ANOVA with Tukey's post-hoc test) by comparing with GlyT1/GlyT2 plus pcDNA). 
GlyT2 (Fig. 6B), but not in the control (transfected with GSK3 $\beta$ plus CDNA), suggesting that the radioactivity was basally incorporated into the expressed transporter (Fig. 6, left panels). GSK3 $\beta$ overexpression increased the ${ }^{32} \mathrm{Pi}$ incorporation into GlyT1 protein and decreased that of GlyT2. The co-expression with the dominant negative form of GSK3 $\beta$ suppressed these alterations in the phosphorylation status of both transporters. The differences in labeling were not due to any differences in protein expression as evidenced when the gels were rehydrated, immunoblotted, and probed with anti-GlyT1 and anti-GlyT2 antibodies to visualize the amount of expressed transporter (Fig. 6, left panels). Comparable immunoreactivity was observed in the different extracts independent of the construct transfected. The radioactive bands had a similar pattern along the lane to that observed for the immunoreactivity, supporting the hypothesis that the phosphorylated protein was itself the transporter rather than an associated protein coimmunoprecipitating with the transporter. The intensity of autoradiographic bands was quantified and normalized for protein expression (Fig. 6, right panels). Together, these assays indicated that there is differential regulation of GSK3 $\beta$ in the activity, plasma membrane expression, and phosphorylation status of the transporters.

\subsection{Pharmacological inhibition of GSK3 $\beta$ affects glycine transporters in neuron primary cultures of brainstem and spinal cord}

To obtain more insights into the GSK3 $\beta$ regulation we determined whether endogenously expressed GlyT1 and GlyT2 were functionally modulated through GSK3 $\beta$ as in heterologous systems. We examined the effect of the kinase inhibitors in primary neuronal cultures from the rat brainstem and spinal cord (E16 embryos) where the glycine transporters and GSK3 $\beta$ co-localized in the same cell (Fig. S1). Cells were treated with lithium chloride and with the specific GSK3 $\beta$ inhibitor TDZD-8 $(10 \mu \mathrm{M})$. Both compounds showed a consistent stimulating effect on glycine transport mediated by GlyT1, while the GlyT2 activity was clearly inhibited (Fig. 7A). The effect was observed after $1 \mathrm{~h}$ of treatment and continued for approximately $6 \mathrm{~h}$ (data not shown). Furthermore, the cell surface proteins labeled with the non-permeant reagent sulfo-NHS-biotin after treatment, consistently showed a decrease of GlyT2 protein and, by contrast, an increase in the amount of GlyT1 at the plasma membrane (Fig. 7).
A

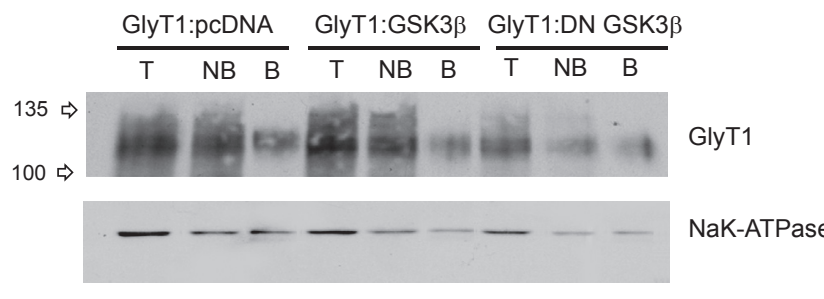

B

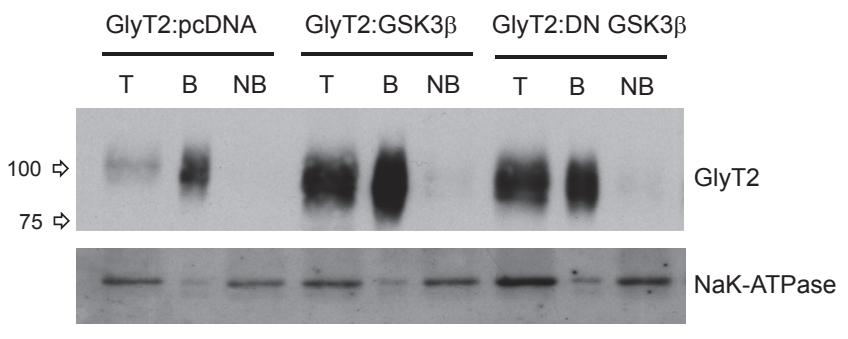

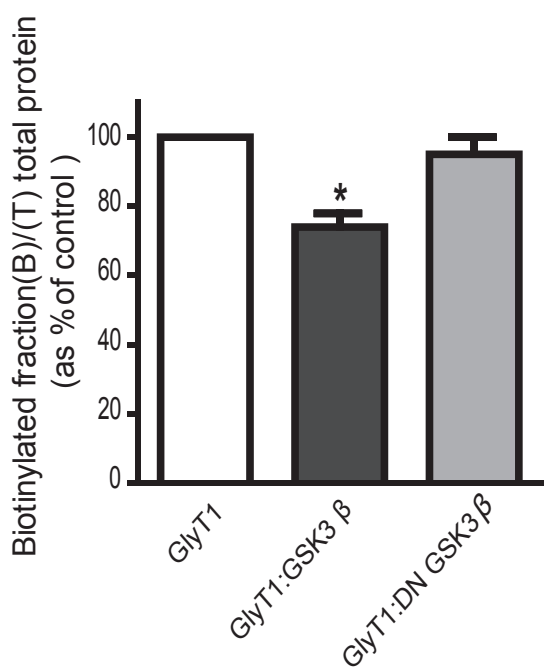

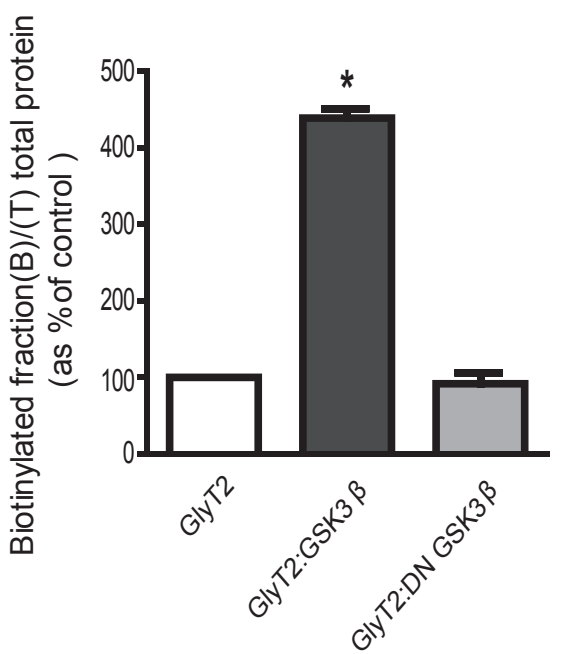

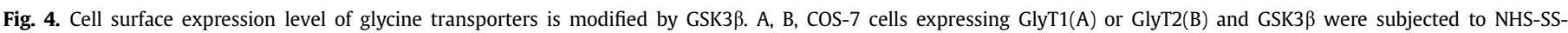

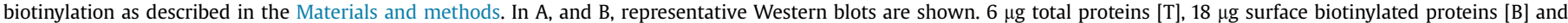

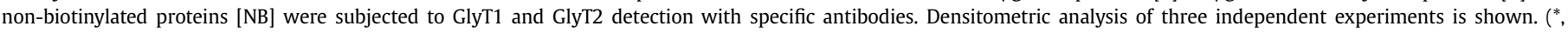
statistically significantly different, $p<0.05$; ANOVA with Tukey's post-hoc test by comparing with GlyT1/GlyT2 plus pcDNA). 
Altogether, Xenopus oocytes, COS-7 cells and neuronal cultures results suggest that GSK3 $\beta$ exerts a down- and up-regulation of each transporter, which consequently modulates the glycinergic neurotransmission.

\section{Discussion}

The present study reveals a completely novel function of GSK3 $\beta$, the differential modulation of the $\mathrm{Na}^{+}$-coupled glycine transporters GlyT1 and GlyT2. Considering that the function of these proteins is critical for the proper functioning of glycinergic and the NMDAmediated glutamatergic synapses, the results of this work increase the knowledge of the regulatory mechanisms of excitatory and inhibitory neurotransmission in the CNS with a potential pathophysiological impact.

In this work we have shown that the co-expression of GSK3 $\beta$ with GlyT1 or GlyT2 leads to a down- and up-regulation of the transporter activity, respectively, in two different heterologous
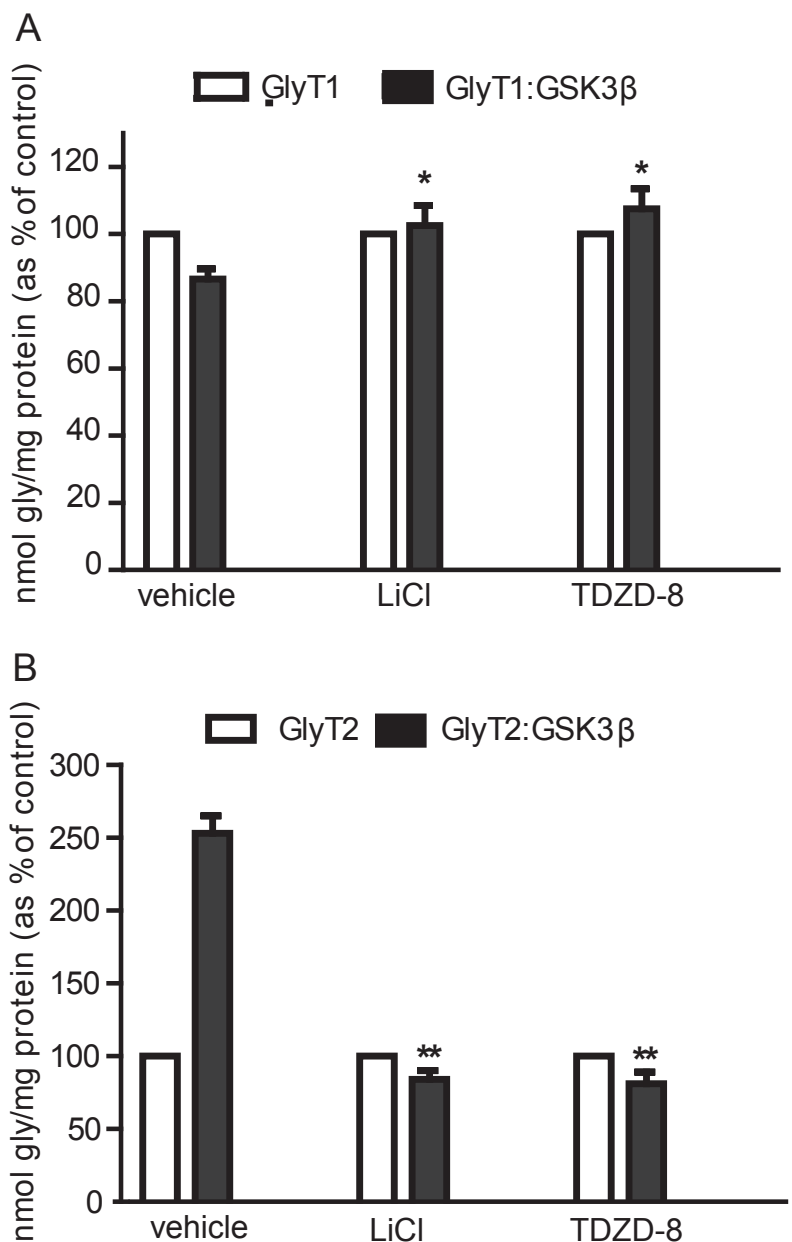

Fig. 5. GSK3 inhibitors reverse the GSK3 $\beta$ effects on glycine transporters. A, COS-7 cells expressing GlyT1 or coexpressing GlyT1 and GSK3 $\beta$ (A) were incubated with lithium chloride $(5 \mathrm{mM})$ and TDZD-8 $(10 \mu \mathrm{M})$ prior to measuring glycine uptake. This was measured for $10 \mathrm{~min}$ at $1 \mu \mathrm{M}\left[{ }^{3} \mathrm{H}\right]$ glycine. B, COS-7 cells expressing GlyT2 or coexpressing GlyT2 and GSK3 $\beta$ were treated as in A. Histograms represent the mean \pm SEM (error bars) of four experiments. 100\% glycine transport by GlyT1 in vehicle, LiCl and TDZD-8 treatment were $6.5,6.9$ and $5.9 \mathrm{nmol}$ gly/mg protein/10 min, respectively. $100 \%$ glycine transport by GlyT2 in vehicle, $\mathrm{LiCl}$ and TDZD- 8 treatment correspond to $0.8, \quad 0.6$ and $0.9 \mathrm{nmol}$ gly $/ \mathrm{mg}$ protein/10 $\mathrm{min}$, respectively. GlyT1:GSK3 $\beta$ or GlyT2:GSK3 $\beta$ treatment values were compared with GlyT1:GSK3 $\beta$ or GlyT2:GSK3 $\beta$ vehicle values by using ANOVA with Tukey's post-hoc test *, statistically significantly different $p<0.05$. expression systems, COS-7 cells and X. laevis oocytes. These functional changes are consistent with a decrease and increase of the GlyT1 and GlyT2 levels at the plasma membrane, respectively. The specificity of these changes is supported by the antagonism exerted by a catalytically inactive form of the kinase and through inhibitors of GSK3 $\beta$ kinase, such as TDZD-8 and lithium. Additional evidence of the opposite modulation carried out by the overexpression of GSK3 $\beta$ on GlyT1 and GlyT2, are provided by the results of the pharmacological inhibition of GSK3 $\beta$ in neuron primary cultures of brainstem and spinal cord. Both, the activity and cell surface expression of the endogenous transporters showed changes as a result of neuronal kinase inhibition. Altogether, the different modulation of GlyT1 and GlyT2 exerted by GSK3 $\beta$ in neuronal cultures and in cells expressing the recombinant proteins indicates that the observed glycine transport regulation is indeed the consequence of specific effects on the transporters.

Glycogen synthase kinase 3 (GSK3 $\beta$ ) is highly expressed in the CNS and is considered to be a multifunctional serine/threonine kinase involved in neuronal development, mood stabilization, and neurodegeneration. Recently it has been proposed that GSK3 $\beta$ plays a major role in plasticity at excitatory and inhibitory synapses in the CNS (Bradley et al., 2012). The underlying molecular mechanisms involved are, at least partially, via the regulation of the function and trafficking of NMDA and AMPA receptors (Chen et al., 2007; Bradley et al., 2012; Wei et al., 2010). Data from this work add an additional control point of glutamatergic neurotransmission by GSK3 $\beta$. Considering that GlyT1 is the main regulator of glycine availability near to NMDA receptors, the modulation of its activity and cell surface presence by GSK3 $\beta$ could indirectly modulate the NMDARmediated glutamatergic synapses. Moreover, GlyT2 is the main supplier of glycine for constitutive vesicle refilling through active reuptake of the neurotransmitter to the terminal. This process is absolutely crucial to preserve the quantal glycine content inside the synaptic vesicles and is critical for regulating inhibitory synaptic strength (Gomeza et al., 2003b; Rousseau et al., 2008; Apostolides and Trussell, 2013). Therefore, because GlyT2 activity regulates the glycinergic synaptic strength, the new modulatory mechanism by GSK3 $\beta$ described here is of great physiological relevance. The results of this work suggest that constitutively active endogenous GSK3 $\beta$ is important for stabilizing and/or controlling the expression of functional GlyTs on the neural cell surface. The data described here and elsewhere (Chen et al., 2007; Bradley et al., 2012; Wei et al., 2010) could represent a more general process underlying CNS synaptic plasticity whereby GSK3 $\beta$ controls neuronal proteins that are crucial for the proper functioning of inhibitory and excitatory fast neurotransmission.

It is interesting to note that GlyT1 and GlyT2 are modulated in a coordinated and opposite way as that shown in this work by different mechanisms and situations. An example is the purinergic control of GlyT1 and GlyT2 through P2Y receptors in brainstem and spinal cord neurons. This mechanism promotes the functioning of inhibitory pathways over the excitatory ones in the spinal cord which would result in anti-nociception. This has been interpreted as part of a homeostatic mechanism in pain processing that relies on the control exerted by GlyT1 and GlyT2 in the balance of the neuronal excitation and inhibition of some neuronal circuits such as the dorsal spinal cord (Jiménez et al., 2011). In addition, it has been described that the chronic treatment of a clinically relevant concentration of ethanol evokes differential adaptive responses on the activity and membrane expression levels of recombinant GlyT1 and GlyT2 transporters. These changes are part of the glutamatergic and glycinergic neurotransmission alterations produced by alcoholic intoxication and contribute to the depressive effects induced by ethanol in the CNS (Nuñez et al., 2000). 
All of the above demonstrates that the physiologic function of the GlyTs is finely controlled by different mechanisms and that these proteins are pharmacologic targets of choice for the treatment of pathologies underlying an imbalance of neuronal excitation and inhibition. A paradigmatic example is schizophrenia resulting from deficient glutamate signaling via NMDA receptors (Javitt, 2007; Coyle, 2012). The inhibition of glycine transport by GlyT1 near to NMDAR is a current pharmacologic strategy (Kristensen et al., 2011) as evidenced by the numerous synthetic GlyT1 inhibitors currently in advanced clinical trials. One of these inhibitors, bitopertin, is currently in Phase III clinical trials (Harvey and Yee, 2013). Developing a GlyTs based pharmacology is being considered for future application to pathologies other than schizophrenia, such as alcohol dependence, neuropathic pain, epilepsy and mood disorders. Taking into consideration that changes in the expression and activity of GSK3 $\beta$ have been found in conditions such as schizophrenia (Kozlovsky et al., 2001, 2002; Jope, 2003; Lovestone et al., 2007; Emamian, 2012), mood disorders (Eldar-Finkelman, 2002; Jope, 2011), and addictive behaviors (Miller et al., 2009, 2010), the modulation of GlyTs by GSK3 $\beta$ described in this work could be of great pathophysiological significance. Furthermore, a better understanding of the mechanisms that control the activity of these glycine transporters will help to elucidate its true value as pharmacologic targets.

We have provided evidence that GSK3 $\beta$ is involved in the phosphorylation status of GlyT1 and GlyT2. The decrease in
GlyT2 ${ }^{32} \mathrm{Pi}$ incorporation upon co-expression with the kinase suggests that the modulation could be mediated by other kinases, probably inhibited by GSK3 $\beta$, or alternatively through the activation of a phosphatase. By contrast, GlyT1 phosphorylation status appears to be increased in the presence of GSK3 $\beta$, although we could not conclude that is a direct phosphorylation. These results do not allow conclude that changes in the phosphorylation status of GlyTs by overexpression of GSK3 are the direct cause of the observed alterations in the trafficking of the transporters. However, the parallels changes in the activity, plasma membrane expression and phosphorylation of GlyT1 and GlyT2 seem to be relevant to the mechanism underlying the regulation by GSK3 $\beta$.

\section{Conclusions}

This study describes a novel function of GSK3 $\beta$, the opposite modulation of the glycine transporters GlyT1 and GlyT2. GSK3 $\beta$ induces a decrease in GlyT1 and an increase in GlyT2 levels at the plasma membrane. These changes are antagonized by a catalytically inactive form of the kinase and by inhibitors of GSK3 $\beta$ (lithium chloride and TDZD-8). Therefore, GSK3 $\beta$ function appears to be an important factor for stabilizing and/or controlling the expression of functional GlyTs on the neural cell surface.

Our results suggest that constitutively active GSK3 $\beta$ is important in stabilizing and/or controlling the expression of functional GlyTs
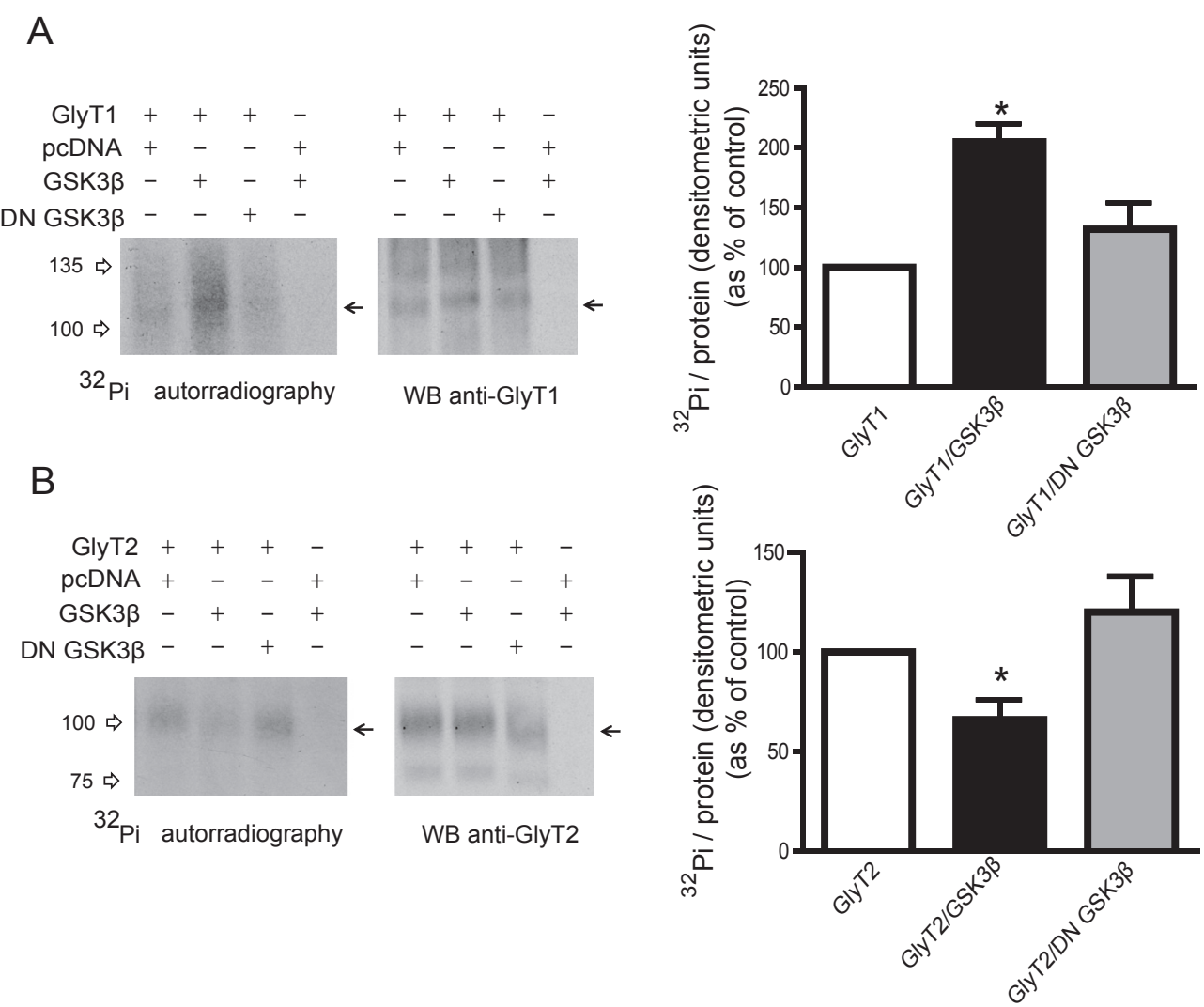

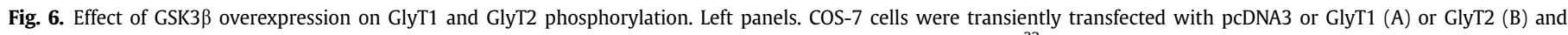

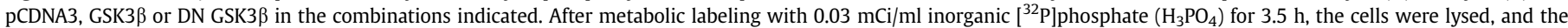

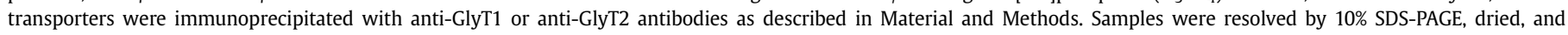

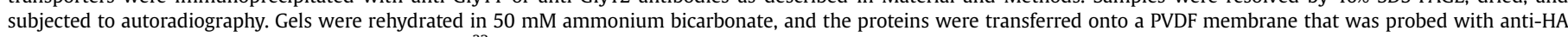

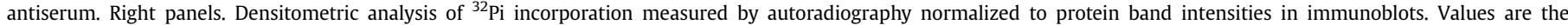

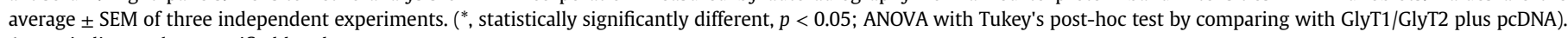
Arrow indicates the quantified band. 
A

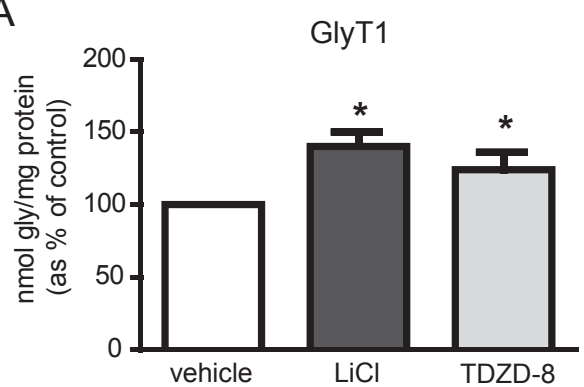

C
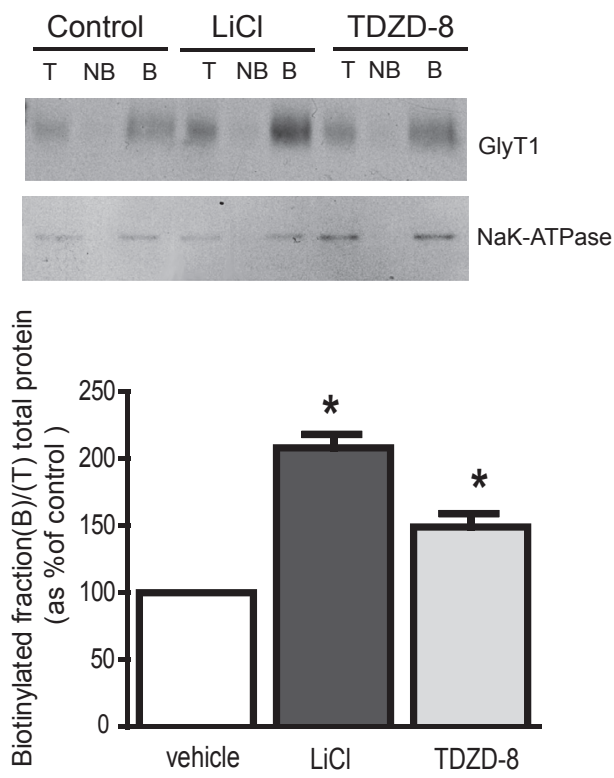

B
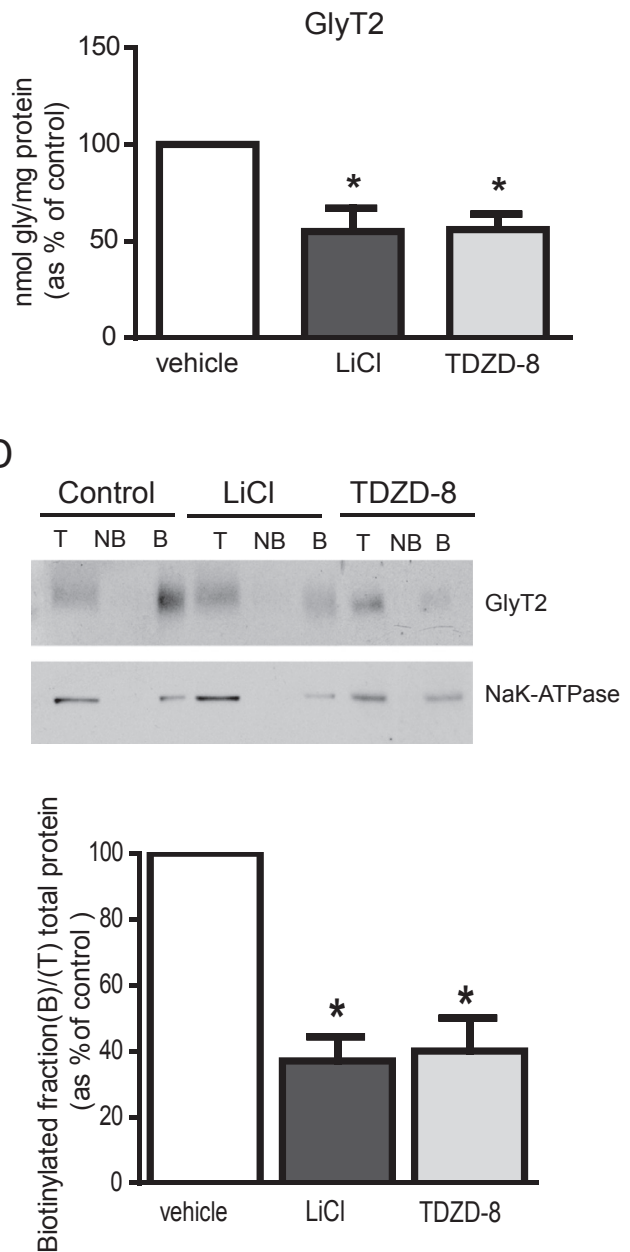

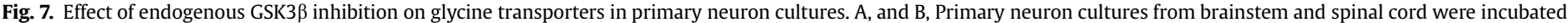

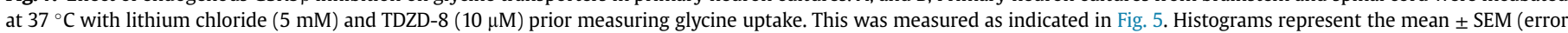

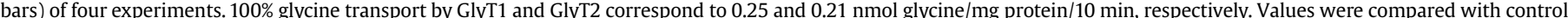

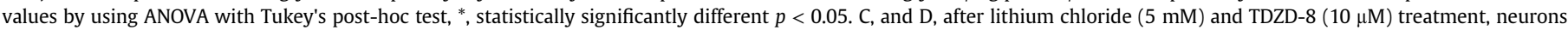

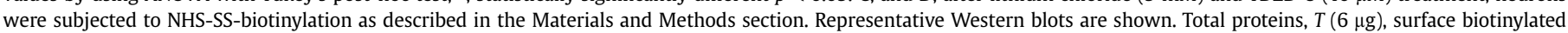

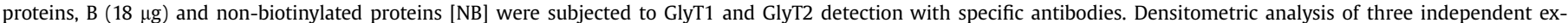
periments is displayed. ${ }^{*}$, statistically significantly different $p<0.05$ ANOVA with Tukey's post-hoc test by comparing with control).

on the neural cell surface. This could represent a more general process underlying CNS synaptic plasticity where GSK3 $\beta$ controls neuronal proteins that are crucial to the proper functioning of inhibitory and excitatory fast neurotransmission.

\section{Acknowledgments}

The authors are grateful to Dr. Félix Hernández for providing GSK3 $\beta$ plasmids.

This work was supported by the Spanish Dirección General de Investigación Científica y Técnica SAF2011-29961 and by an institutional grant from the 'Fundación Ramón Areces'. The group is member of the Network for Rare Disease Research (Centro de Investigación Biomédica en Red de Enfermedades Raras).

\section{Appendix A. Supplementary data}

Supplementary data related to this article can be found at http:// dx.doi.org/10.1016/j.neuropharm.2014.09.023.

\section{References}

Apostolides, P.F., Trussell, L.O., 2013. Rapid, activity-independent turnover of vesicular transmitter content at a mixed glycine/GABA synapse. J. Neurosci. 33, 4768-4781.

Aragón, C., López-Corcuera, B., 2003. Structure, function and regulation of glycine neurotransporters. Eur. J. Pharmacol. 479, 249-262.

Aragón, C., López-Corcuera, B., 2005. Glycine transporters: crucial roles of pharmacological interest revealed by gene deletion. Trends Pharmacol. Sci. 26, $283-286$.

Balaraman, Y., Limaye, A.R., Levey, A.I., Srinivasan, S., 2006. Glycogen synthase kinase-3beta and Alzheimer's disease: pathophysiological and therapeutic significance. Cell. Mol. Life Sci. 63, 1226-1235.

Bradley, C.A., Peineau, S., Taghibiglou, C., Nicolas, C.S., Whitcomb, D.J., Bortolotto, Z.A., Kaang, B.K., Cho, K., Wang, Y.T., Collingridge, G.L., 2012. A pivotal role of GSK-3 in synaptic plasticity. Front. Mol. Neurosci. 5, 13. http:// dx.doi.org/10.3389/fnmol.2012.00013.

Carta, E., et al., 2012. Mutations in the GlyT2 gene (SLC6A5) are a second major cause of startle disease. J. Biol. Chem. 287, 28975-28985.

Chen, P., Gu, Z., Liu, W., Yan, Z., 2007. Glycogen synthase kinase 3 regulates Nmethyl-D-aspartate receptor channel trafficking and function in cortical neurons. Mol. Pharmacol. 72, 40-51.

Coyle, J.T., 2012. NMDA receptor and schizophrenia: a brief history. Schizophr. Bull. 38, 920-926.

de Juan-Sanz, J., Nunez, E., López-Corcuera, B., Aragón, C., 2013a. Constitutive endocytosis and turnover of the neuronal glycine transporter GlyT2 is dependent on ubiquitination of a C-terminal lysine cluster. PLoS ONE 8 (3), e58863. 
de Juan-Sanz, J., Nuñez, E., Villarejo-Lopez, L., Perez-Hernandez, D., RodriguezFraticelli, A.E., Lopez-Corcuera, B., Vazquez, J., Aragon, C., 2013b. $\mathrm{Na}^{+} / \mathrm{K}^{+}$-ATPase is a new interacting partner for the neuronal glycine transporter GlyT2 that down-regulates its expression in vitro and in vivo. J. Neurosci. 33, 14269-14281.

de Juan-Sanz, J., Zafra, F., López-Corcuera, B., Aragón, C., 2011. Endocytosis of the neuronal glycine transporter GlyT2: role of membrane rafts and protein kinase C-dependent ubiquitination. Traffic 12, 1850-1867.

Doble, B.W., Woodgett, J.R., 2003. GSK-3, tricks of the trade for a multi-tasking kinase. J. Cell Sci. 116, 1175-1186.

Eldar-Finkelman, H., 2002. Glycogen synthase kinase3, an emerging therapeutic target. Trends Mol. Med. 8, 126-132.

Emamian, E.S., 2012. AKT/GSK3 signaling pathway and schizophrenia. Front. Mol. Neurosci. 5, 33. http://dx.doi.org/10.3389/fnmol.2012.00033.

Eulenburg, V., Becker, K., Gomeza, J., Schmitt, B., Becker, C.M., Betz, H., 2006. Mutations within the human GlyT2 (SLC6A5) gene associated with hyperekplexia. Biochem. Biophys. Res. Commun. 348, 400-405.

Fornes, A., Nunez, E., Alonso-Torres, P., Aragon, C., Lopez-Corcuera, B., 2008. Trafficking properties and activity regulation of the neuronal glycine transporter GlyT2 by protein kinase C. Biochem. J. 412, 495-506.

Geerlings, A., Nunez, E., Lopez-Corcuera, B., Aragon, C., 2001. Calcium- and syntaxin 1-mediated trafficking of the neuronal glycine transporter GlyT2. J. Biol. Chem. 276, 17584-17590.

Gill, J.L., James, V.M., Carta, E., Harris, D., Topf, M., Scholes, S.F., Hateley, G., Harvey, R.J., 2012. Identification of congenital muscular dystonia 2 associated with an inherited GlyT2 defect in Belgian Blue cattle from the United Kingdom. Anim. Genet. 43, 267-270.

Gimenez, C., et al., 2012. A novel dominant hyperekplexia mutation Y705C alters trafficking and biochemical properties of the presynaptic glycine transporter GlyT2. J. Biol. Chem. 287, 28986-29002.

Gomeza, J., Hulsmann, S., Ohno, K., Eulenburg, V., Szoke, K., Richter, D., Betz, H., 2003a. Inactivation of the glycine transporter 1 gene discloses vital role of glial glycine uptake in glycinergic inhibition. Neuron 40, 785-796.

Gomeza, J., Ohno, K., Hulsmann, S., Armsen, W., Eulenburg, V., Richter, D.W., Laube, B., Betz, H., 2003b. Deletion of the mouse glycine transporter 2 results in a hyperekplexia phenotype and postnatal lethality. Neuron 40, 797-806.

Harvey, R.J., Yee, B.K., 2013. Glycine transporters as novel therapeutic targets in schizophrenia, alcohol dependence and pain. Nature 12, 866-885.

Hooper, C., Killick, R., Lovestone, S., 2008. The GSK3 hypothesis of Alzheimer's disease. J. Neurochem. 104, 1433-1439.

Javitt, D.C., 2007. Glutamate and schizophrenia: phencyclidine, $N$-methyl-d-aspartate receptors, and dopamine-glutamate interactions. Int. Rev. Neurobiol. 78, 69-108.

Javitt, D.C., 2008. Glycine transport inhibitors and the treatment of schizophrenia. Biol. Psychiatry 63, 6-8.

Jiménez, E., Zafra, F., Pérez-Sen, R., Delicado, E.G., Miras-Portugal, M.T., Aragón, C., López-Corcuera, B., 2011. P2Y purinergic regulation of the glycine neurotransmitter transporters. J. Biol. Chem. 286, 10712-10724.

Jope, R.S., 2011. Glycogen synthase kinase-3 in the etiology and treatment of mood disorders. Front. Mol. Neurosci. 4, 16. http://dx.doi.org/10.3389/fnmol. 2011.00016.

Jope, R.S., 2003. Lithium and GSK-3, one inhibitor, two inhibitory actions, multiple outcomes. Trends Pharmacol. Sci. 24, 441-443.

Kaech, S., Banker, G., 2006. Culturing hippocampal neurons. Nat. Protoc. 1, 2406-2415.

Klein, P.S., Melton, D.A., 1996. A molecular mechanism fort the effect of lithium on development. Proc. Natl. Acad. Sci. U. S. A. 93, 8455-8459.

Kozlovsky, N., Belmaker, R.H., Agam, G., 2001. Low GSK- 3 activity in frontal cortex of schizophrenic patients. Schizophr. Res. 52, 101-105.

Kozlovsky, N., Belmaker, R.H., Agam, G., 2002. GSK-3 and the neurodevelopmental hypothesis of schizophrenia. Eur. Neuropsychopharmacol. 12, 13-25.

Kremer, A., Louis, J.V., Jaworski, T., Van Leuven, F., 2011. GSK3 and Alzheimer's disease: facts and fiction. Front. Mol. Neurosci. 4, 17. http://dx.doi.org/10.3389/ fnmol. 2011. 00017.
Kristensen, A.S., Andersen, J., Jørgensen, T.N., Sørensen, L., Eriksen, J., Loland, C.J., Strømgaard, K., Gether, U., 2011. SLC6 neurotransmitter transporters: structure, function, and regulation. Pharmacol. Rev. 63, 585-640.

Leroy, K., Brion, J.P., 1999. Developmental expression and localization of glycogen synthase kinase-3 $\beta$ in rat brain. J. Chem. Neuroanat. 16, 279-293.

Liu, Q.R., Lopez-Corcuera, B., Mandiyan, S., Nelson, H., Nelson, N., 1993. J. Biol. Chem. 268, 22802-22808.

Lovestone, S., Killick, R., DiForti, M., Murray, R., 2007. Schizophrenia as a GSK-3 dysregulation disorder. Trends Neurosci. 30, 142-149.

Maixner, D.W., Gao, M., Weng, H.R., 2014. Glycogen synthase kinase 3 beta regulates glial glutamate transporter protein expression in the spinal dorsal horn in rats with neuropathic pain. Exp. Neurol. 252, 18-27.

Miller, J.S., Tallarida, R.J., Unterwald, E.M., 2010. Inhibition of GSK3 attenuates dopamine D1 receptor agonist-induced hyperactivity in mice. Brain Res. Bull. 82, 184-187.

Miller, J.S., Tallarida, R.J., Unterwald, E.M., 2009. Cocaine-induced hyperactivity and sensitization are dependent on GSK3. Neuropharmacology 56, 1116-1123.

Mines, M.A., Yuskaitis, C.J., King, M.K., Beurel, E., Jope, R.S., 2010. GSK3 influences social preference and anxiety-related behaviors during social interaction in mouse modelo fragile X syndrome and autism. PLoS ONE 5, e9706. http:// dx.doi.org/10.1371/journal.pone.0009706.

Nuñez, E., Alonso-Torres, P., Fornes, A., Aragon, C., Lopez-Corcuera, B., 2008. The neuronal glycine transporter GlyT2 associates with membrane rafts: functional modulation by lipid environment. J. Neurochem. 105, 2080-2090.

Nuñez, E., López-Corcuera, B., Martínez-Maza, R., Aragón, C., 2000. Effects of ethano on glycine uptake mediated by the recombinant GlyT2 glycine transporter. Br. J. Pharmacol. 129, 802-810.

Pinard, E., Alanine, A., Alberati, D., Bender, M., Borroni, E., et al., 2010. Selective GlyT1 inhibitors: discovery of [4-(3-fluoro-5-trifluoromethylpyridin-2-yl) piperazin-1-yl][5-methanesulfonyl-2-((S)-2,2,2-trifluoro-1-methylethoxy) phenyl]methanone (RG1678), a promising novel medicine to treat schizophrenia. J. Med. Chem. 53, 4603-4614.

Polter, A., Beurel, E., Yang, S., Garner, R., Song, L., Miller, C.A., Sweatt, J.D. McMahon, L., Bartolucci, A.A., Li, X., Jope, R.S., 2010. Deficiency in the inhibitory serine-phosphorylation of glycogen synthase kinase-3 increases sensitivity to mood disturbances. Neuropsychopharmacology 35, 1761-1774.

Rayasam, G.V., Tulasi, V.K., Sodhi, R., Davis, J.A., Ray, A., 2009. Glycogen synthase kinase 3: more than a namesake. Br. J. Pharmacol. 156, 885-898.

Rees, M.I., Harvey, K., Pearce, B.R., Chung, S.K., Duguid, I.C., Thomas, P., Beatty, S., Graham, G.E., Armstrong, L., Shiang, R., Abbott, K.J., Zuberi, S.M., Stephenson, J.B., Owen, M.J., Tijssen, M.A., van den Maagdenberg, A.M., Smart, T.G., Supplisson, S., Harvey, R.J., 2006. Mutations in the gene encoding GlyT2 (SLC6A5) define a presynaptic component of human startle disease. Nat. Genet. 38, 801-806.

Rousseau, F., Aubrey, K.R., Supplisson, S., 2008. The glycine transporter GlyT2 controls the dynamics of synaptic vesicle refilling in inhibitory spinal cord neurons. J. Neurosci. 28, 9755-9768.

Ryves, W.J., Harwood, A.J., 2001. Lithium inhibits glycogen synthase kinase-3 by competition for magnesium. Biochem. Biophys. Res. Commun. 280, 720-725.

Smith, K.E., Borden, L.A., Hartig, P.R., Branchek, T., Weinshank, R.L., 1992. Neuron 8, 927-935.

Wei, J., Liu, W., Yan, Z., 2010. Regulation of AMPA receptor trafficking and function by glycogen synthase kinase 3. J. Biol. Chem. 285, 26369-26376.

Wildburger, N.C., Laezza, F., 2012. Control of neuronal ion channel function by glycogen synthase kinase-3: new prospective for an old kinase. Front. Mol. Neurosci. 5, 80. http://dx.doi.org/10.3389/fnmol.2012.00080.

Woodgett, J.R., 1990. Molecular cloning and expression of glycogen synthase kinase3/factorA. Embo J. 9, 2431-2438.

Zafra, F., Gomeza, J., Olivares, L., Aragón, C., Giménez, C., 1995. Regional distribution and developmental variation of the glycine transporters GLYT1 and GLYT2 in the rat CNS. Eur. J. Neurosci. 7, 1342-1352. 